\title{
On Language Determinism and Relativity
}

\author{
Susanna Baghdasaryan \\ Armenian State Pedagogical University \\ "All speech, written or spoken, is a dead language, \\ until it finds a willing and prepared hearer."
}

(R.L. Stevenson)

W e would not discover any novelty if we stated that language is the primary means of human communication. However, the language is not just a transmitter of thoughts and ideas, it is also a creator and a reflector. The language paradigm is our most basic metaphor because word creations substitute for the thing signified. As we master words, we often fail to distinguish between verbal symbols and the reality for which they stand. But words can only evoke conceptually what is meant, thereby providing vicarious mental experiences for speaker and hearer. Once acquired, words have the power to mediate what we think, say, and do.

Through language, we have the power to recreate events experienced, but also to talk of things we "know" only indirectly through symbols. Language aids (and sometimes limits) imagination, fantasy, the make-believe. Real or imagined, language can bring into existence even what may not exist at all. And once experienced, directly or indirectly, language becomes a repository for our collective human memory - or at least for the memory of those who share the same tongue - generation after generation.

Language is a double-edged sword: Language communicates, but it also excommunicates. That is, it includes only those who share the system; others are excluded. Likewise, language both liberates and constrains. Our ability to symbolize, for example, allows us to move freely, albeit conceptually, through time and space. We can recall and tell of things past or project into the future merely by uttering words. So great is our faith in words that we can viscerally experience the "reality" of something we never experienced directly at all, whether in the past or the future.

Knowledge is tremendously augmented through language use. Much of schooling and other learning in life is accomplished through language, expanding the limits of what we can know through direct experience alone. Language permits contemplating the impossible and exploring the unfathomable. We talk about concepts as difficult and as abstract as "death," for example, which we can never know directly, at least not in life. It is difficult to imagine what life might be like without our human ability to symbolize, just as it is difficult to imagine how we might think or know differently if we spoke a language other than our native tongue.

When serving as a means of intercultural communication, the cognitive characteristic of the language emerges with vividness, because the language is not a bare unity of meaningful utterances, it is also a carrier of a national character. One may not know Italian, but when listening to a speech utterance in that language closely, one cannot fail to learn about the cheerfulness, artistry, and lightness that characterize that nation. 
Armenian speech may evince a dramatic destiny and solemnity that characterizes the Armenian nation. Thus, language is not just a means of exchanging intercultural data, it is also a good resource of learning more about the given culture.

Because language is considerably more tangible and easier to document than culture, linguists are often better able to analyze and understand their data. Yet, much of what is gleaned from a linguistic perspective about a language informs our understanding of culture. Because language reflects and affects culture, and because both languages and cultures are human inventions, it is not surprising this should be so. A linguistic concept illustrating this point and widely used in the intercultural field (Gudykunst \& Nishida 1989 ) is the notion of etic and emic perspectives (seeing from the outside as a foreigner vs. seeing from the inside as a native). The utility of linguistic insight to intercultural thought is perhaps best supported in the works of Edward Hall and may account for his proposition that "culture is communication" (Hall 1973:97) just as we might add that, "communication is culture". Communicative ability allows cultural development through interaction and communication with other individuals. Language serves as the construct that aids cultural development.

Why is it that we take language for granted, unaware that our native tongue is not merely a "neutral" communication system, but a pervasive medium that directly influences every aspect of our lives? It may be because we seldom need to reflect on our use of language; it has been there for as long as we can remember. And therein lies the power of a different cultural experience. While providing a chance to learn about another way of life, it provokes even more questions about one's own language, culture and worldview.

By giving tangible expression to thought, language enables communication with others. Although speech signals are often part of communicative ability, there are other forms as well - written symbols, signed language and other means. Whichever we use, these are usually combined, forming several interrelated systems:

- a linguistic component (sounds, signs and/or graphemes, forms, and grammar of language);

- a paralinguistic component (tone, pitch, volume, speed, and affective aspects);

- an extralinguistic component (nonverbal aspects such as gestures, movements, grimaces);

- context (sociolinguistic dimension: a repertoire of styles, each appropriate for different situations).

All these are mastered in overlapping stages as part of one's native competence. Understanding these multiple dimensions and their interrelatedness elucidates what is involved when developing competence in a second or third system.

During the past quarter of a century, the notion of communicative competence has increasingly commanded the attention of language teachers and interculturalists alike. For language teachers, it suggests that teaching "language" means more than the linguistic (i.e., grammar) component alone. In practice, however, linguistic considerations often continue to preempt the major portion of time in classroom teaching. For interculturalists, on the other hand, a common approach to communicative competence includes cul- 
ture-specific ethnographic studies based on the work of Hymes' (1972) framework (cf. Carbaugh 1990); as well as attempts to extend this sociolinguistic framework to intercultural interaction (cf. Collier 1989). In these endeavors, however, the language component is often superseded by a focus on the communicative rules of interaction.

Language, i.e. communicative competence (our expanded definition of language), reflects and reinforces a particular view we hold of the world. In linguistic terms, the influence of language on culture and worldview is called language determinism and relativity; in other words, the language we acquire influences the way we construct our model of the world (hence, determinism). And if this is so, other languages convey differing visions of that same world (relativity). This theory, known as the Sapir-Whorfian hypothesis, raises intriguing issues related to cross-cultural effectiveness (Steinfatt 1989; Whorf 1956). In other words the level of effectiveness and appropriateness of an individual's activity in the domain of a foreign culture are viewed under the light of target language competence and incompetence. Some scientists state that there is a significant difference in communicating in one's own language and in the target language on the platform of a foreign culture. They base their judgments on the supposition that target language competence gives a much more clear view of the given linguaculture.

Despite the marvelous diversity and creativity across the linguacultures of the world, the overlap hints at the existence of universals across all, an aspect that researchers have begun to investigate more seriously in recent years. These universals may result from our common humanity, ensured by similar biological and physical possibilities and constraints.

Developing intercultural competence for ourselves and for others is a shared challenge - for language educators and interculturalists alike. Contact with other world views can result in a shift of perspective, along with a concomitant appreciation for the diversity and richness of human beings.

Communication is one of the indispensible particles of the modern life. The effectiveness of that communication determines the development of science and the prosperity of human life. The effective communication is what makes the world an integrated unity and makes the famous novel by Defoe just an intriguing adventure.

\section{References:}

1. Adler, P.S. (1976) Beyond Cultural Identity. // Intercultural Communication. / Ed. by L. Samovar \& R.E. Porter. Belmont, CA: Wadsworth.

2. Brown, R. (1958) Words and Things. New York: The Free Press.

3. Carbaugh, D. (Ed.) (1990) Cultural Communication and Intercultural Contact. Hillsdale, NJ: Lawrence Erlbaum.

4. Fishman, J. (1976) Bilingual Education: An International Sociological Perspective. // Recorded keynote address, 5th International Bilingual Education Conference, San Antonio, TX.

5. Gudykunst, W.B. \& Nishida, T. (1989) Theoretical Perspectives for Studying 
Intercultural Communication. // Handbook of International and Intercultural Communication. / Ed. by Asante \& Gudykunst. Newbury Park, CA: Sage.

6. Hall, E.T. (1973) The Silent Language. New York: Doubleday.

7. Hall, E.T. (1976) Beyond Culture. New York: Doubleday.

8. Hymes, D. (1972) Models of the Interaction of Language and Social Life. II Directions in Sociolinguistics. The Ethnography of Communication. / Ed. by J. Gumperz \& D. Hymes. New York: Holt, Rinehart \& Winston.

9. Steinfatt, T.M. (1989) Linguistic Relativity: Toward a Broader View. // Language, Communication and Culture: Current Directions. / Ed. by S. Ting-Toomey \& F. Korzenny. Newbury Park, CA: Sage.

10. Ting-Toomey, S. \& Korzenny, F. (Eds.) (1989) Language, Communication and Culture: Current Directions. Newbury Park, CA: Sage.

11. Whorf, B.L. (1956). Language, Thought and Reality. Cambridge, MA: MIT Press.

12. Wiseman, R.L. \& Koester, J. (Eds.) (1993) Intercultural Communication Competence. Newbury Park, CA: Sage.

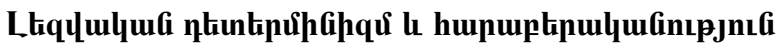

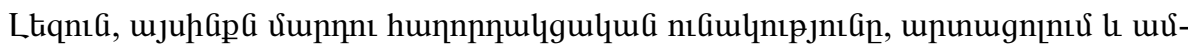

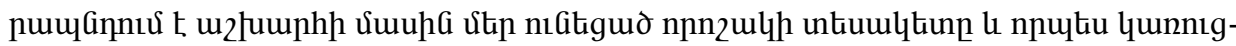

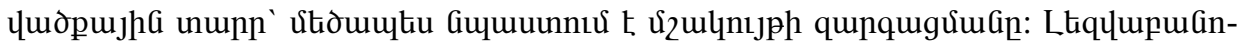

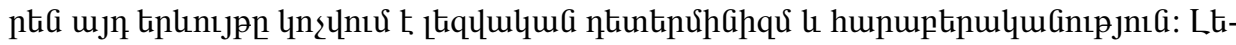

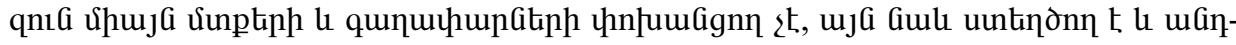

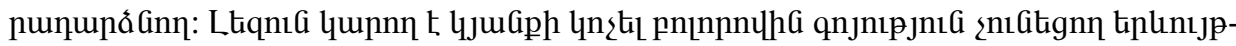

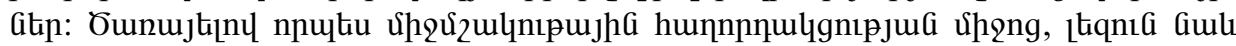

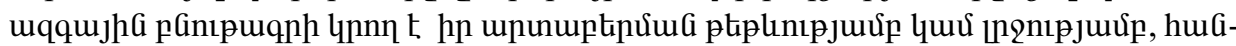

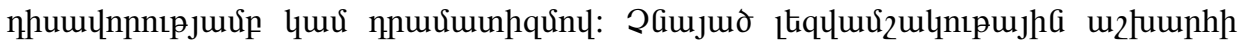

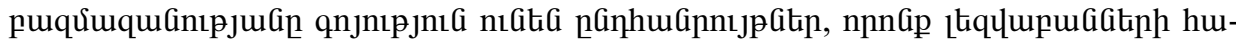

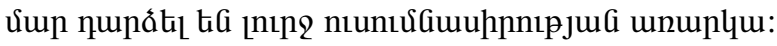

